\title{
A survey to identify barriers in the public health role of community pharmacists
}

\begin{abstract}
Objectives

This survey seeks the opinion of UK community pharmacists to identify barriers in the public health role of community pharmacists.
\end{abstract}

\section{Methods}

This study took the form of a descriptive, cross-sectional survey that generated mostly quantitative data. Questionnaires were mailed to 524 randomly selected community pharmacists from Barnet, London and its surrounding areas, Bedfordshire, Cardiff and Edinburgh. All statistical analyses were performed using the Statistical Package for the Social Sciences (SPSS 19.0).

\section{$\underline{\text { Key findings }}$}

A majority of the respondents identified time pressure and workload (89.7\%, C.I. \pm 4.94$)$; lack of patients' records $(78.6 \%$, C.I. \pm 6.66$)$; insufficient funding from the government $(75.2 \%$, C.I. \pm 7.01 ); lack of understanding by healthcare providers of the training and skill sets of pharmacists $(73.7 \%$, C.I. \pm 7.25$)$; and lack of understanding by the public of the training and skill sets of pharmacists $(72.7 \%$, C.I. \pm 7.29$)$, as the main barriers in enhancing the public health role of community pharmacists in the UK. Male respondents were more likely to agree that 'insufficient funding' was a barrier $\left(p=.006\right.$; Eta, $\left.\eta^{2}=.053\right)$. There was a negative correlation between 'age of respondents' and respondents agreeing that pharmacists should develop their own expertise in public health $[\rho=-.185 ; p=.029]$. Free text comments also highlighted a number of barriers, which included, among other things, time pressure and workload, commercial pressure from employers, lack of collaboration between healthcare professionals, and inadequate funding.

\section{Conclusions}

Several barriers associated with the public health role of community pharmacists have been identified as hindering the enhancement of this role. To enable the profession to evolve fully from product-oriented services to patient-centred care, many of these barriers will need to be tackled.

\section{$\underline{\text { Introduction }}$}

A number of UK studies have confirmed the role of pharmacists in public health. ${ }^{1-6}$ However, a number of studies have also identified barriers hindering the public health role of 
community pharmacists. These include: time pressure and workload; ${ }^{4,7-10}$ the training of pharmacists and their staff; 4,10,11,12 and inadequate remuneration and lack of support from stakeholders..$^{4,9,10,11,13}$ At the same time, safety concerns ${ }^{10,14}$ and lack of documentation ${ }^{10,15,16}$ have also been recognised as barriers hindering the provision of public health services from community pharmacies.

However, as many of the identified barriers have originated from studies that were conducted overseas, some of their findings may not be generalisable to the UK. This survey seeks the opinion of UK community pharmacists to identify barriers hindering the public health role of community pharmacists in the UK.

\section{Methods}

This study was approved by the programme approval panel (PAP) and research ethics subcommittee (RESC) of the University and took the form of a descriptive, cross-sectional survey that generated mostly quantitative data. Items were selected and included in the questionnaire based on the identified themes in the review of literature and information, ${ }^{10}$ with assistance from J.O. and J.P. (content or face validity). ${ }^{17}$ The questionnaire was designed to take approximately 20 minutes to complete, with assurance of the confidentiality of the responses. The questionnaire was pilot tested for content, clarity and format of the questions on a group of 150 randomly selected community pharmacists in Bedfordshire area, England, as listed on the NHS Choices website. ${ }^{18}$ The purpose of the study was explained, with the response rate for the pilot study being 39\% (59/150), after two reminders (three weeks apart). The Cronbach's alpha was also calculated to estimate the internal consistency of the pilot survey questionnaire. Based on the 56 items tested on the pilot questionnaire, the SPSS reliability test indicated that the Cronbach's alpha was 0.787. As this number (0.787) was greater than 0.7 , there was no need to alter the questionnaire. ${ }^{19}$

The questionnaire was designed to collect the demographic characteristics of the respondents, such as gender, age, and years of post-qualification experience. ${ }^{20}$ The 
respondents were also requested to give their opinions on the perceived barriers to enhancing the public health role of community pharmacists in the UK, using a scale of 1-5 (1 = disagree, 2 = strongly disagree, $3=$ neither agree nor disagree, $4=$ agree, $5=$ strongly agree). ${ }^{20}$ J.O. and J.P. approved the questionnaire before its use. For the main study, the questionnaires were mailed with covering letters to 385 randomly selected community pharmacists from Barnet, London, and its surrounding areas, Cardiff and Edinburgh. The covering letter introduced the researchers, summarised the purpose of the study and guaranteed confidentiality. Two reminders were sent at three-week intervals to nonresponders to enhance the response rate. All statistical analyses were performed using the most recent version of the Statistical Package for the Social Sciences (SPSS 19.0).

\section{Results}

Eighty-eight usable responses were collected in the main survey, representing a response rate of $22.8 \%$ [88/385]. However, when these were combined with the returned pilot questionnaires (59) [59/150], the combined response rate for all questionnaires received became $28.05 \%(147 / 524)$.

\section{Pharmacists' characteristics}

Both men (73 [50\%]), and women (73) responded to the survey, C.I. \pm 8.09 . Their age-range distribution is shown in Figure 1, which indicates that the youngest, as well as highest number of respondents, were aged between $20-29$ years $(26.5 \%$, C.I. \pm 7.12$)$, while the oldest, as well as the fewest number of respondents, were aged between $70-79$ years $(2.0 \%$, C.I. \pm 2.26 ). The role distribution of the respondents (Figure 2 ) indicated that a majority of the respondents were working as employee community pharmacists $(76.9 \%$, C.I. \pm 6.8$)$.

\section{Survey responses}

\section{Barriers to the public health role of the community pharmacist}

In terms of the barriers to enhancing the public health role of community pharmacists in the UK [see Table 1], the majority of the respondents identified insufficient training of pharmacists in public health $(66.5 \%$, C.I. \pm 7.64$)$; the lack of professional autonomy for 
pharmacists $(66.9 \%$, C.I. \pm 7.64$)$; the lack of input from public health practitioners $(68.9 \%$, C.I. $\pm 7.52)$; the lack of support from public health practitioners $(69.3 \%$, C.I. \pm 7.54$)$; and difficulty in communicating with other public health providers $(69.5 \%$, C.I. \pm 7.5$)$ as barriers.

As well as the aforesaid, the majority of respondents also identified the lack of support from GPs (68.2\%, C.I. \pm 7.56$)$; insufficient funding from the government (75.2\%, C.I. \pm 7.01$)$; time pressure and workload (89.7\%, C.I. \pm 4.94$)$; the lack of patients' records (78.6\%, C.I. \pm 6.66$)$; the lack of instrumentation $(55.9 \%$, C.I. \pm 8.06$)$; the lack of understanding by the public of the training and skill sets of pharmacists (72.7\%, C.I. \pm 7.29$)$; and the lack of understanding by healthcare providers of the training and skill sets of pharmacists $(73.7 \%$, C.I. \pm 7.25$)$ as barriers. Conversely, the majority of respondents did not accept that language barriers $(53.5 \%$, C.I. \pm 8.13$)$ and safety concerns of patients $(51.1 \%$, C.I. \pm 8.12$)$ were barriers to enhancing the public health role of community pharmacists.

In addition to the quantitative responses, the questionnaire also provided an option for the respondents to supply, in a free text format, comments about what they considered as barriers to enhancing the public health role of community pharmacists. The barriers that were highlighted varied and included issues such as funding challenges, time pressure, commercial pressure from employers, etc:

\section{$\underline{\text { Various }}$}

"Lack of co-ordinated approach by utilising all parties; lack of understanding and acceptance of health promotion before treatment; as well as ring-fenced funding arrangements" [E390].

\section{Commercial Pressure}

“Undue pressure to meet targets by pharmacists' employers, due to their selfish financial gain" [P9].

\section{Follow up}

"Follow up is difficult to find out why a patient hasn't continued, e.g. NRT. Time constraints to phone each individual patient who hasn't returned" [E454]. 


\section{Conflict of interest}

"GP and GP practices don't want pharmacies in their team - conflict of interest" [B37].

"GPs think we are taking money from them by providing a service" [RC185].

\section{Publicity}

“Government/NHS should emphasise pharmacists' roles more publicly - ever-likely as mandatory for those using NHS services regularly, e.g. mandatory MUR for all on long-term medications" [P133].

\section{Underutilised}

"Pharmacist skill set is heavily underutilised" [PR100].

\section{Commercialism}

"Get rid of target-driven services" [P103].

In the case of three other respondents, engagement was seen as a solution to eliminate some of the barriers:

"Pharmacists need to be more pro-active" (P8)

"Inform the public, e.g., $A+B$ to be taken at regular intervals specified on prescription, every 8 hourly, 6 hourly. A + B resistance..." [PR19].

"Engagement with NHS England" (P79)

Three other respondents also highlighted the need for capacity development within the work force:

"Time (\&) skills" [RB144].

"Direct funding to pharmacists and autonomy" [P112].

"On job training with pay benefits" [P147].

According to four respondents, ensuring consistency in service delivery across sectors and/or locations can also help to tackle some of the identified barriers:

"All training should be the same regardless of location, so all extra training can be used anywhere in the country" [P103]. 
"Firstly, pharmacists themselves need to quantify and specify what they're able to do for the public and patients rather than just taking on what GPs don't want to do anymore for no more money" [E382].

On the other hand, ten of the respondents highlighted the need for collaboration between healthcare professionals, as well as with government bodies. For some, this will also mean GPs delegating certain services to pharmacists, various healthcare professionals seeing pharmacists more as colleagues, rather than as competitors, as well as recognising each others' roles and abilities. Some of these comments are included below:

"Make medical students aware of (the) need to work together for (the) common good of patients at student level" [PR04].

"Training GPs, etc., and pharmacists together. All groups need to be aware of skills of other. Time - there's a lot to do already!" [RE336].

Two of the respondents would, however, like pharmacies to employ more than one pharmacist in a pharmacy, which will, for example, allow pharmacists' roles to be split between dispensing activities and clinical (and public health) activities:

"Have two pharmacists on duty at all times, (one) dispensing (and the other) clinical. Make it law, so pharmacy chains are forced into doing this" [B63].

"More pharmacists per branch" [RE406].

Yet according to another two respondents, the delegation of pharmacists' roles to other health teams might be the way forward:

"Allow dispensers to take the pressure off pharmacists, so they take more responsibility for dispensing scripts and pharmacists can concentrate more on other services" [RE 372].

"Cut down on pharmacy schools and phase out the need for pharmacists and let nurses, doctors and dispensers run local dispensaries" [P12]

In addition, another area of emphasis for many of the respondents was on improving funding for community pharmacy public health activities, which eleven of them identified as a barrier to enhancing the role of pharmacists in public health.

"More resources and training provided. GPs get paid for such services. We should too!" [P149]. 
"More funding for public health services. More incentives for pharmacists carrying out services rather than company targets" [P97].

At the same time, there were several and wide-ranging suggestions for more support and training for pharmacists (twenty respondents); enhancing awareness of the services that community pharmacists were providing (eighteen respondents); community pharmacists becoming more proactive with public health; improving communication between healthcare professionals; tackling the undervaluing of pharmacists, as well as reducing community pharmacists' workload. Some of these comments are reported below:

\section{Support and training}

"The introduction of protected learning time such as how GPs currently allowed to close the practice once a month for 2 hours to allow for training" [UK32]

"Integrating into undergraduate training/provide training in community pharmacy post qualification...so it becomes more commonplace training...structure...similar to in hospital setting, maybe? Increase public awareness by public campaign" [P11].

\section{Awareness}

"Local Pharmaceutical Committees [LPCs] communicate with fund-holders, e.g., Public Health England, CAN, Clinical Commissioning Groups [CCGs], etc, and actively promote community pharmacy. National bodies, e.g., Pharmaceutical Services Negotiating Committee [PSNC] to negotiate more national services" [PR28].

"Other healthcare professionals to be educated in role of pharmacist. More freedom given to pharmacists when consulting patients, e.g. a formulary similar to a nurse" [PR54].

\section{Proactive with public health activities}

"Pharmacists need to understand the bigger picture and must be proactive in promoting the services - public health" [Respondent B121].

"An 'ask your pharmacist' campaign on Facebook, buses and newspapers" [C257].

\section{Communication}

"Better communication between healthcare professionals. Training together with 
other healthcare professionals" [RC191].

"Better communication and understanding of the skill set of pharmacists" [RB148].

However, when the questionnaire asked community pharmacists about how essential it was that patients get public health services from community pharmacies, some $50 \%$ of the respondents (C.I. \pm 8.15 ) indicated that this was 'very essential'; some $26.4 \%$ indicated 'essential' (C.I. \pm 7.18$) ; 14.6 \%$ indicated 'quite essential' (C.I. \pm 5.76$) ; 8.3 \%$ said, 'sometimes' (C.I. \pm 4.5$)$, while one respondent $(0.7 \%$, C.I. \pm 1.62$)$ disagreed. On the negative aspects of the public health services from community pharmacies and how they could be improved, some of the feedback also included that pharmacists were devalued; problems of commercial pressure from employers; lack of training; funding challenges; lack of privacy and premises arrangement; distractions and lack of commitment from community pharmacists; lack of awareness (fourteen respondents); lack of time (twenty-two respondents); workload and unmanageable stress levels (ten respondents); inconsistency in service delivery; as well as the issue of isolation.

\section{Various}

"Time and resources. If we were given funding for one person to do public health services, then we would help patients" [P149].

"Lack of support to carry out further clinical roles and over-step by pharmaceutical companies causing pharmacists to lose their identity in the sector" [PR91].

\section{Devalued}

"Considered as shopkeepers" [P79].

"Pharmacists hand out medicines and that is all they do" [P12].

\section{Lack of training}

"Lack of training for MCAs (Multi-compartment Compliance Aids)" [P81].

"Lack of training. Non-regular pharmacists" [RC196]. 


\section{Funding}

"Indifference on the part of pharmacists due to lack of funding" [P137].

"Too many free items and services available. Many people just take advantage of that without any real improvement" [RE354].

\section{$\underline{\text { Premises }}$}

"Small space and little time. Second pharmacist (is needed)" [RE406].

"Premises - need improving" [P49].

\section{Distraction/Lack of commitment}

"Pharmacist(s) too bogged down with dispensing and not focused on the other services" [B121].

"People can easily abuse the system - visit multiple pharmacies for free services. There should be an electronic registration in place like Scottish Electronic Minor Ailments System (eMAS)" [E454].

\section{Lack of awareness}

"Public awareness of services offered - more publicity and campaigns. Premises some premises are not fit for purpose. Standards need to be raised so that delivery of services would convey professionalism" [P118].

"Archaic mentality of what pharmacists do" [C255].

"Negative connotation, due to association with 'commerce', that is, 'just a shopkeeper' [B30]."

\section{Lack of time}

"Juggling between essential, advanced and enhanced services" [P23].

"Lack of time means services are done half-heartedly" [RC244].

\section{Workload/stress}


"Extra workload on top of overcrowded daily work" [C198].

"Workload of pharmacists is dangerously high, so potential issues with more work" [C239].

\section{Inconsistency}

"Inconsistent - national programs should be developed" [B109].

"Companies that own pharmacies should not be involved in activities which show conflict of interest, e.g. selling cigarettes" [B123].

\section{Isolation}

"No mechanism for sharing with other members (of the healthcare profession) what we have done" [C264].

Interestingly, some eighty-six percent of the respondents (C.I., \pm 5.83 ) also agreed with the statement that 'the public health role of community pharmacists in the UK is still undeveloped in the $21^{\text {st }}$ century'. For the respondents that said 'yes' to this question, some of the reasons they gave were about the quality of the services provided by community pharmacies, hence, the problem of trust; lack of consistency in service delivery; lack of time to deliver public health services; community pharmacists not feeling professionally empowered enough to provide public health services; lack of training; lack of awareness; difficulty adapting to changing needs; feeling undervalued and unrecognised; and lack of focus. Yet some of the respondents talked about the accessibility of community pharmacy practices.

\section{Quality/trust}

"Not enough quality service offered by majority of community pharmacies" [P97] "Public do not see pharmacy as place to go for public health issues" [PR43]

\section{Inconsistency}

"Too much variation between areas, doesn't allow us to build continuity of service" [B115]. 
"People still visit their GP for minor ailments. One reason for this could be because prescriptions are free in Wales" [C257].

\section{Lack of time}

"We have a lot of experience and knowledge, but not the time to provide the services" [RC244].

"So much more can be done, but time and funding can be a barrier" [P21]

\section{Empowerment}

"Increase in pharmacists' powers needed to better contribute to public health greater access to public records, plus information" [P133]

"More freedom in terms of prescribing" [P130].

\section{$\underline{\text { Training }}$}

"(Pharmacists) too overqualified for their present roles" [P17].

"We are expected to provide a service without specific teaching or training - all we do is learning on our own or through one's own experiences" [E382].

\section{Awareness}

"Pharmacists can do a lot more to contribute to public health. Our biggest hurdle is educating the public that we are the first point of call and recognised by NHS" [RB27].

\section{Adaptation}

"Pharmacist(s) are not adapting to the changing needs of this service. Pharmacist(s) \{are\} really placed to provide public health services" [B121].

"Less checking of prescriptions and more time to counsel" [RE385]

\section{$\underline{\text { Access }}$}

"Pharmacists and staff have direct contact with patients, so they can talk to them. 
Community pharmacists have known patient base, which makes it easier for them to approach the patients for health issues" [P110].

"Easy access for the public" [RB144].

\section{Undervalued/lack of recognition}

"So much knowledge gone to waste" [RC162].

"Shopkeeper, not seen as a professional person" [B86].

"Massive, trained workforce, (but, are) criminally underused and unpaid" [B30].

\section{$\underline{\text { Focus }}$}

"Yes, pharmacy could do more, but can't do everything" [C169].

"There is still too much focus on high volume dispensing" [E347].

\section{$\underline{\text { Tests for significance and correlation of variables }}$}

Tests for significance indicated that the male respondents (median $=5.0$ ) were more likely than the female respondents (median $=4.0$ ) to agree that 'insufficient funding from the government' was a barrier to enhancing the public health role of community pharmacists ( $p$ $\left.=.006 ; \mathrm{Eta}, \eta^{2}=.053\right)$. Regarding a 'language barrier', those aged between $70-79$ (median $=$ 1.0) were less likely than other respondents to see this as a barrier $\left(p=.046 ; \eta^{2}=.078\right.$; Total median $=2.0$ ). Yet those respondents who described themselves as 'pharmacy contractors' (median $=4.5)$, 'other' (median $=5.0)$ and 'superintendent pharmacists' (median $=5.0$ ) were more likely than other respondents to agree that 'insufficient funding from the government' was a barrier $\left(p=.049 ; \eta^{2}=.096\right.$; Total median $\left.=4.0\right)$.

In terms of the correlation of variables (Pearson's coefficient, $\rho$ ), our male respondents were more likely than our female respondents to agree that the lack of support from public health practitioners was a barrier to enhancing the public health role of community pharmacists $[\rho=-.195 ; p=.020]$. Also, there were negative correlations between the 'age of respondents' and their likelihood of agreeing that difficulties in recruiting patients $[\rho=-$ 
$.168 ; p=.043]$; high dropout rates for public health services $[\rho=-.179 ; p=.031]$; low success rates for public health services $[\rho=-.215 ; p=.010]$; and safety concerns among pharmacists $[\rho=-.181 ; p=.030]$ were barriers to enhancing the public health role of community pharmacists. There was also a negative correlation between the 'age of respondents' and respondents agreeing that pharmacists should develop their own expertise in public health $[\rho=-.185 ; p=.029]$.

In terms of location, respondents from Bedfordshire were more likely than respondents from Cardiff, Edinburgh and Barnet (in that order) to agree that 'lack of support from public health practitioners' was a barrier in enhancing the public health role of community pharmacists $[\rho=.195 ; p=.021]$. In the same order, respondents from Bedfordshire were more likely to also agree that 'lack of patients' records' was a barrier $[\rho=.179 ; p=.033$ ].

\section{$\underline{\text { Discussion }}$}

This survey has confirmed many of the barriers identified elsewhere ${ }^{4,10}$ Notably, there is a need to address many of the identified barriers hindering the public health role of community pharmacists in the UK, such as the community pharmacy environment, which sometimes may not be suitable for the delivery of public health services; ${ }^{21}$ the negative perceptions by both the general public and other health providers of pharmacists' competencies; privacy and confidentiality in pharmacies; as well as time pressure and a high dispensing workload.

Still, there also seems to be a need to address issues such as the UK healthcare system and its policies towards the public health role of the pharmacist, inadequate training of pharmacists in public health, lack of documentation of activities and inadequate financial support. ${ }^{4,10,16,22}$ The need for better funding demands closer attention, particularly when you also consider that the male respondents were, on the average, less happy with the present funding arrangements $\left(p=.006 ; \eta^{2}=.053\right)$ than the female respondents. To encourage younger pharmacists to participate in public health services, direct remuneration to pharmacists might be a game changer $\left(p=.043 ; \eta^{2}=.078\right)$. Yet it seems reasonable that policy makers and other stakeholders should also be aware of the differences that existed in 
the responses (based on the role of the respondent) that 'insufficient funding from the government' was a barrier to enhancing the public health role of community pharmacists ( $p$ $\left.=.049 ; \eta^{2}=.096\right)$.

There is also a need to tackle other barriers, which include the lack of professional autonomy for pharmacists, ${ }^{21}$ the lack of input from public health practitioners, the lack of support from GPs and public health practitioners, difficulty in communicating with other public health providers, the lack of patients' records, and the lack of understanding by the public and healthcare providers of the training and skill sets of pharmacists. In addition, it seems necessary to minimise commercial pressures from employers, difficulties in following up with patients, the conflict of interest that seems to exist between pharmacists and GPs, as well as the underutilisation of pharmacists' skills. Nevertheless, as suggested by some of the respondents, it is possible to resolve many of the barriers by, for example, getting rid of target-driven services, opening up channels of engagement between pharmacists and stakeholders, reducing professional isolation, ensuring consistency in service delivery across sectors and localities, enhancing collaboration between community pharmacists and other healthcare providers, and ensuring that more than one pharmacist works in community pharmacies at any time, as seen in Italy. In addition, role delegation between pharmacists and other healthcare professionals and pharmacy support staff will also be necessary. Yet there is also a need for pharmacists themselves to be more proactive, assertive and committed to public health activities.

Other challenges faced by community pharmacists in their aspiration to provide public health services relate to the lack of a well-defined career structure and clear progression channels, an unacceptable work-life balance, ${ }^{23}$ the unavailability of individually contracted community pharmacists, ${ }^{24}$ and the declining ownership of community pharmacies by pharmacists. ${ }^{22,25}$ The conflict of interest which one of our respondents raised as a barrier to enhancing the public health role of community pharmacists in the UK, i.e. "GP and GP practices don't want pharmacies in their team - conflict of interest" [B37], could be managed by encouraging GP practices to employ more pharmacists as recently proposed by 
the Royal Pharmaceutical Society (RPS) and the Royal College of General Practitioners (RCGP). ${ }^{26}$ According to a recent publication, ${ }^{27}$ closer ties with general practice - and primary, secondary, tertiary, mental health and social care - are essential to improve the contribution of pharmacists to patient care and to secure better prospects for the profession.

Not surprising, the underutilisation of pharmacists has often been described as a huge waste of resources, as well as a drain on the intellectual skills of pharmacists, ${ }^{24}$ particularly in recent times, when other healthcare professionals are struggling to cope with demands which could easily be managed by pharmacists. From some of the comments in this study, it was obvious that UK community pharmacists would like the underutilisation of pharmacists to be reversed. Yet to address some of these challenges, the profession might also need to consider a recent proposal to separate the dispensing role of pharmacists from the pharmacy/public health services role, ${ }^{28}$ while at the same time, promoting the establishment of healthy living pharmacies in the UK. ${ }^{29}$

Supporting the notion that there is a variation in the relationships between GPs and community pharmacists across the UK is the revelation that respondents from Edinburgh (median $=3.0$ ) were less likely than other respondents to agree that 'lack of support from GPs' was a barrier to enhancing the role of community pharmacists in public health $(p<$ $.001 ; \eta^{2}=.157 ;$ Total median $\left.=4.0\right)$. This variation might need to be investigated further and then managed. While the majority of survey respondents felt that the lack of patients' records $(78.6 \%$, C.I. \pm 6.66$)$ was a barrier to enhancing the public health role of the community pharmacist, a much lower number of respondents $(52.1 \%$, C.I. \pm 8.14$)$ identified the lack of documentation of public health interventions as a barrier to enhancing this role. For some time, a UK professional association has advocated that community pharmacists be given access to patients' Summary Care Records. ${ }^{30,31}$ According to the professional association, the availability of 'Summary Care' records will allow the application of highly developed clinical skills that only a pharmacist can perform. ${ }^{31}$

The recent announcement that SCR access will soon be rolled out to community pharmacists across England is not only an encouraging development, ${ }^{32}$ but will hopefully 
help to enhance both the clinical, as well as the public health skills of pharmacists. Despite the benefits, it has, however, been noted that access to Summary Care health records is not risk free, particularly as it may not only increase the risk of prosecution, but could also increase the risk of civil claims for any injury caused by a dispensing error in some circumstances. ${ }^{33}$

\section{Recommendation for further studies}

This study identified a number of significant differences and correlations between variables, particularly in terms of gender, the role of the respondents and the location of practice. Further research in these areas might be needed to identify how tackling these differences could help to enhance the public health role of community pharmacists in the UK.

\section{Limitations}

The response rate for this study was very low. However, its impact on the generalisability of the results was minimised by the relatively large sample size used in the study and the study's reporting of free text comments, as well as confidence intervals (C.I.), in the results. A low response rate is, however, not uncommon for health surveys. ${ }^{34-36}$ The main contributing factor to the low response rate might have been the length of the survey questionnaire (which listed sixty-three items, including free text options). Again, the fact that the researchers did not have multiple contacts for the respondents or offer any financial incentives also might have affected the survey response rate negatively. ${ }^{37}$ Still, it is possible that the poor response rate recorded in this study could be a reflection of how disengaged UK community pharmacists are with the profession..$^{38,39}$

\section{Conclusions}

There are numerous opportunities for community pharmacists in public health. ${ }^{10,40-42}$ However, several barriers associated with the public health role of community pharmacists have been identified as hindering the enhancement of this role; one of them is that the UK's community pharmacy public health practice is still operating at a basic level. ${ }^{1,2,4}$ Although the pharmacy profession is gradually evolving from product-oriented to patient-centred care, with pharmacists now contributing to micro-level public health activities, there 
continues to be an unmet need for UK pharmacists in macro-level public health functions. ${ }^{43}$ To achieve this desired objective, both in the UK and globally, it will be necessary to enhance, among other things, both the undergraduate and the post-graduate public health (including clinical pharmacy) ${ }^{44}$ training and skills of pharmacists, as well as the career structure of community pharmacists. In addition, it will be necessary to enable the development of a mixed market in community pharmacy practice by encouraging more pharmacists to be employed in GP practices, as well as for the government to contract public health services directly to individual or group pharmacists, who are not constrained by the burden of the dispensing role. Yet pharmacists should also be encouraged to use newer technologies, ${ }^{44}$ including social media, to enhance their public health practice. 


\section{References:}

1. Anderson C. Health promotion by community pharmacists: Perceptions, realities and constraints. J Social Adm Pharm 1998; 15: 10-22.

2. Anderson C, Blenkinsopp A. Community pharmacy's contribution to improving public health: Learning from local initiatives. Pharm J 2003; 271: 623-625.

3. Blenkinsopp A et al. Evaluation of feasibility and acceptability of a community pharmacy health promotion scheme - views of users and providers. Health Educ J 2002; 61: 52-69.

4. Agomo $C$. The role of community pharmacists in public health: A scoping review of the literature. J Pharm H Serv Res 2012; 3: 25-33.

5. Solutions for Public Health. Community Pharmacy and Public Health. 2013; http://www.sph.nhs.uk/sph-documents/community-pharmacy-and-public-health-finalreport [accessed 28 August 2015].

6. Public Health England. Consolidating and Developing the Evidence Base and Research for Community Pharmacy's Contribution to Public Health: a Progress Report from Task Group 3 of the Pharmacy and Public Health Forum. London: Public Health England, 2014.

7. O'Loughlin J et al. The role of community pharmacists in health education and disease prevention: A survey of their interests and needs in relation to cardiovascular disease. Prev Med 1999; 28: 324-31.

8. Ursell VC et al. Community pharmacy involvement in public health provision: Current perceptions and future directions. Pharm J 1999; 263: R53.

9. Agomo C et al. An investigation of nicotine replacement therapy provision by community pharmacists in Wandsworth Primary Care Trust, London. Pharm J 2006; 277: 609-611.

10. Agomo C, Ogunleye J. An investigation of strategies enhancing the public health role of community pharmacists - a review of knowledge and information. J Pharm H Serv Res 2014; 5: 135-145.

11. Kotecki JE et al. Health promotion beliefs and practices among pharmacists. J Am Pharm Assoc 2000; 40: 773-779.

12. Watson L et al. A survey of community pharmacists on prevention of HIV and hepatitis B and C: Current practice and attitudes in Grampian. J Publ H Med 2003; 25: 13-18.

13. Le $P$, Hotham ED. Exploring the dissonance between business and public health policy: Pharmacy and the provision of opioid pharmacotherapies and clean needles in rural settings. Int J Pharm Practic 2006; 14: 63-70.

14. Peterson GM et al. Harm minimization strategies: Opinions of health professionals in 
rural and remote Australia. J Clin Pharm Therap 2007; 32: 497-504.

15. Hogue MD et al. Pharmacist involvement with immunizations: A decade of professional advancement. J Am Pharm Assoc 2006; 46: 168-182.

16. Saramunee $\mathrm{K}$ et al. How to enhance public health service utilization in community pharmacy: General public and health providers' perspectives. 2012;

http://www.sciencedirect.com/science/article/pii/S1551741112000745 [accessed 31 August 2015].

17. Oparah AC, Arigbe-Osula EM. Evaluation of community pharmacists' involvement in primary health care. Tropical J Pharm Res 2002; 1: 67-74.

18. NHS Choices. Find Pharmacy Services. 2015; http://www.nhs.uk/ServiceSearch/Pharmacy/LocationSearch/10 [accessed 16 June 2015].

19. Nunnaly J. Psychometric Theory. New York: McGraw-Hill, 1978.

20. Oparah AC, Okojie OO. Health promotion perceptions among community pharmacists in Nigeria. Int J Pharm Practic 2005; 13: 213-221.

21. Agomo C. Why UK pharmacy must adapt to the increasing demands of professionalism in practice. Int J Pharm Practic 2012; 20: 320-323.

22. Bush J et al. The corporatization of community pharmacy: Implications for service provision, the public health function, and pharmacy's claims to professional status in the United Kingdom. Res Soc Admin Pharm 2009; 5: 305-318.

23. Agomo $\mathrm{C}$. Why improving the work-life balance of pharmacists might benefit employers and the profession. J Pharm H Serv Res 2012; 3: 179-181.

24. Scottish Government. Prescription for excellence: A vision and action plan for the right pharmaceutical care through integrated partnerships and innovation 2013. 2013;

http://www.scotland.gov.uk/Resource/0043/00434053.pdf [accessed 31 August 2015].

25. Agomo C. Why partnerships may be a magic wand. Pharm J 2012; 288: 8.

26. Robinson S. Employ pharmacists in GP surgeries, urge leadership bodies. Pharm J 2015; 294: 353.

27. Butterfield E. Pharmacists in GP practices is a vital next step for the profession. Pharm J 2015; 294: 354.

28. Smith J et al. Now or never: Shaping pharmacy for the future London: Royal Pharmaceutical Society, 2013.

29. Kennedy B. PHE commits to doubling HLPs in five years. 2015; 
http://www.chemistanddruggist.co.uk/news/phe-renews-commitment-pharmacy [accessed 4 September 2015].

30. Royal Pharmaceutical Society. Shaping pharmacy for the future: Pharmacist access to the Patient Health Record. 2014;

http://www.rpharms.com/policy-pdfs/patient-health-

record.pdf?utm source=Royal+Pharmaceutical+Society\&utm medium=email\&utm campai gn=5838599 190615-Summary+care+announcement\&dm i=EQ,3H53B,1SA9H,CGOBM,1 [accessed 4 September 2015].

31. Pharmacists' Defence Association. Summary care records. Insight - community pharmacist edition 2015; Spring 2015: 14.

32. Health and Social Care Information Centre [HSCIC]. Summary Care Record access to be rolled out to community pharmacies. 2015; http://psnc.org.uk/our-news/summary-carerecord-access-to-be-rolled-out-to-community-pharmacies/ [accessed 4 September 2015].

33. Sukkar E. Q\&A: Pharmacy regulation and the law. Pharm J 2014; 293: 596.

34. Cook JV et al. Response rates in postal surveys of healthcare professionals between 1996 and 2005: An observational study. BMC H Serv Res 2009; 9: Article 160.

35. Cline RR. Data collection methods. In: Aparasu RR, ed. Research Methods for Pharmaceutical Practice and Policy. London: Pharmaceutical Press, 2011: 143-157.

36. DiPietro NA et al. Public health content in didactic and experiential curricula of U.S. Doctor of Pharmacy programs. Int J Pharm Edu Practic, 2011; 7: 1-14.

37. Dillman DA. Mail and Internet Surveys: The tailored design method. New York: John Wiley \& Sons, 2000.

38. Madlom OM. Embarrassing election turnout is cause for concern. 2013; http://www.pharmaceutical-journal.com/opinion/correspondence/-embarrassing-electionturnout-is-cause-for-concern/11122559.article [accessed 5 August 2015].

39. Cartwright T. Members alienated from voting in RPS elections. 2015; http://www.pharmaceutical-journal.com/opinion/correspondence/members-alienatedfrom-voting-in-rps-elections/20068989.article [accessed 5 August 2015].

40. Bjorkman I et al. Health promotion at Swedish pharmacies - views of the staff. Pharm Practic 2008; 6: 211-218.

41. Department of Health. Healthy Lives, Healthy People: Our Strategy for Public Health in England. Norwich: Stationery Office, 2010. (Cm; 7985).

42. Department of Health. Equity and Excellence: Liberating the NHS. Norwich: Stationery 
Office, 2010. (Cm; 7881).

43. Truong $\mathrm{H}$, Patterson BY. Professional and educational initiatives, supports, and opportunities for advanced training in public health. Am J Pharm Edu 2010; 74: 122.

44. Robinson S. Chief Pharmacists: Pharmacy's future is 'clinical and digital'. Pharm J 2015; 295: 267. 


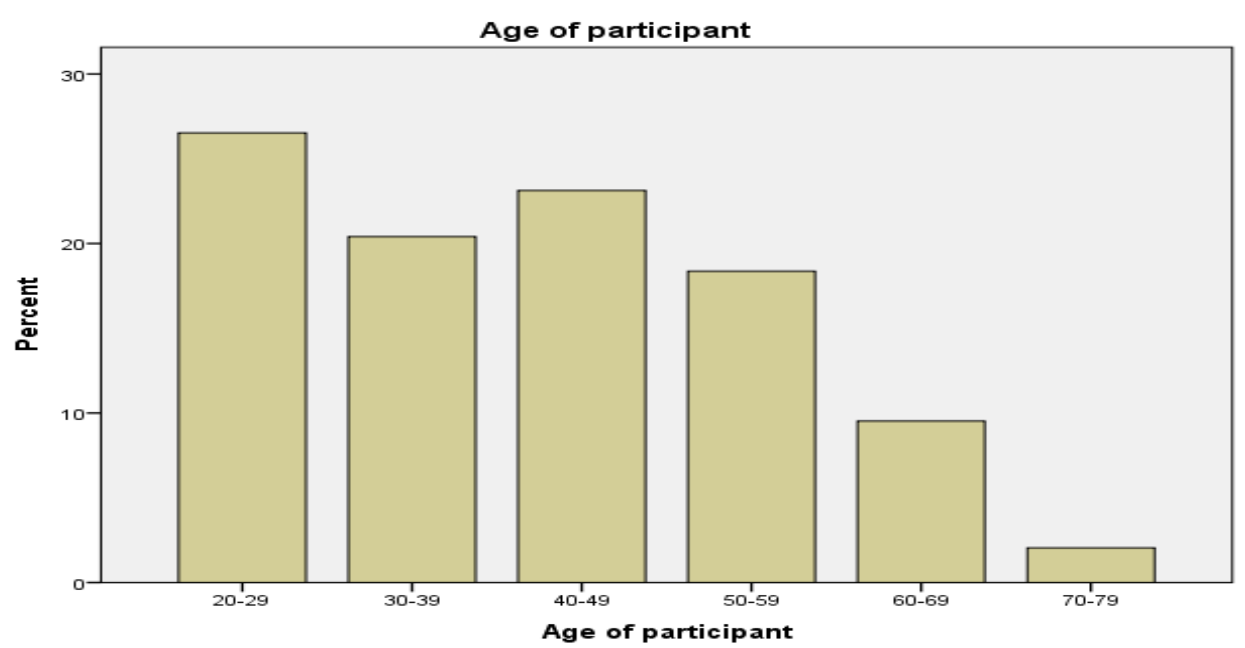

Figure 1: Age of participants

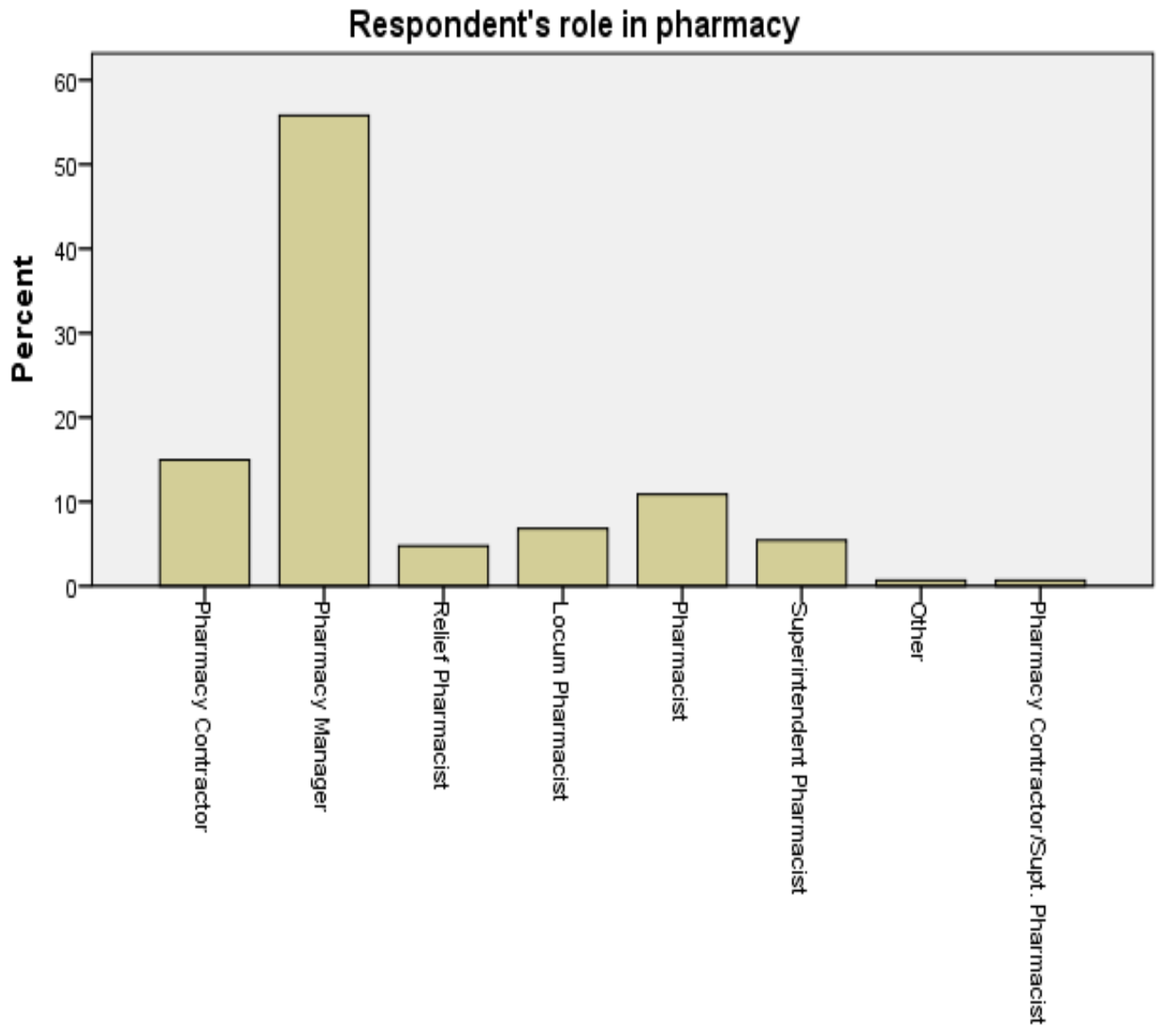

Respondent's role in pharmacy

Figure 2: Respondent's role in pharmacy 
Table 1: Barriers to enhancing the public health role of community pharmacists $(n=147)$.

\begin{tabular}{|c|c|c|c|c|c|}
\hline Responses & $\begin{array}{l}\text { Disagree } \\
\text { (\%) }\end{array}$ & $\begin{array}{l}\text { Strongly } \\
\text { disagree } \\
\text { (\%) }\end{array}$ & $\begin{array}{l}\text { Neither } \\
\text { agree } \\
\text { nor } \\
\text { disagree } \\
\text { (\%) }\end{array}$ & $\begin{array}{l}\text { Agree } \\
\text { (\%) }\end{array}$ & $\begin{array}{l}\text { Strongly } \\
\text { agree } \\
\text { (\%) }\end{array}$ \\
\hline Insufficient training of pharmacists in $\mathrm{PH}$ ? $(\mathrm{n}=146)$ & 11.0 & 4.8 & 17.8 & 51.4 & 15.1 \\
\hline Insufficient skill of pharmacists in $\mathrm{PH}$ ? $(\mathrm{n}=146)$ & 17.1 & 11.6 & 21.9 & 41.1 & 8.2 \\
\hline Lack of professional autonomy for pharmacists? $(n=145)$ & 8.3 & 2.8 & 22.1 & 42.8 & 24.1 \\
\hline Difficulties in recruiting patients? $(n=145)$ & 13.8 & 6.9 & 20.0 & 42.8 & 16.6 \\
\hline Lack of demand for public health services? $(n=145)$ & 28.3 & 18.6 & 27.6 & 20.0 & 5.5 \\
\hline High drop rates for public health services? $(n=145)$ & 11.0 & 9.0 & 35.9 & 32.4 & 11.7 \\
\hline Low success rates for public health services? $(n=144)$ & 25.0 & 13.2 & 31.3 & 24.3 & 6.3 \\
\hline Lack of input from public health practitioners? $(n=145)$ & 6.2 & 2.1 & 22.8 & 50.3 & 18.6 \\
\hline Lack of support from public health practitioners? $(n=143)$ & 8.4 & 1.4 & 21.0 & 47.6 & 21.7 \\
\hline Difficulty in communicating with other PH providers? $(n=144)$ & 11.1 & 3.5 & 16.0 & 55.6 & 13.9 \\
\hline Lack of support from GPs? $(n=145)$ & 7.6 & 2.8 & 21.4 & 37.9 & 30.3 \\
\hline Insufficient funding from the government? $(n=145)$ & 8.3 & 2.1 & 14.5 & 33.8 & 41.4 \\
\hline Difficulty in fee collection? $(n=145)$ & 15.2 & 6.2 & 29.7 & 34.5 & 14.5 \\
\hline Time pressure and workload? $(n=145)$ & 2.1 & 2.8 & 5.5 & 35.2 & 54.5 \\
\hline Safety concerns among pharmacists? $(n=145)$ & 13.1 & 8.3 & 29.7 & 33.1 & 15.9 \\
\hline Safety concerns by GPs? $(n=145)$ & 20.7 & 12.4 & 37.2 & 20.7 & 9.0 \\
\hline Safety concerns of patients? $(n=145)$ & 35.2 & 15.9 & 30.3 & 15.2 & 3.4 \\
\hline Lack of patients' records? $(n=145)$ & 4.8 & 4.8 & 11.7 & 46.2 & 32.4 \\
\hline Lack of documentation of interventions? $(n=144)$ & 11.1 & 6.3 & 30.6 & 39.6 & 12.5 \\
\hline Physical design of community pharmacies? $(n=145)$ & 22.8 & 6.9 & 31.7 & 24.1 & 14.5 \\
\hline Misperception that counselling is not needed? $(n=145)$ & 20.0 & 9.7 & 22.1 & 30.3 & 17.9 \\
\hline Lack of instrumentation? $(n=145)$ & 11.7 & 5.5 & 26.9 & 48.3 & 7.6 \\
\hline Language barrier? $(n=144)$ & 37.5 & 16.0 & 27.8 & 12.5 & 6.3 \\
\hline Lack of understanding by the public? ( $n=143$ ) & 7.0 & 5.6 & 14.7 & 51.0 & 21.7 \\
\hline Lack of understanding by HC providers? $(n=141)$ & 7.1 & 3.5 & 15.6 & 54.6 & 19.1 \\
\hline
\end{tabular}


